\title{
Influence of Tourism Development of Local Real Estate Price in China
}

\author{
Jing Tie \\ International Business School, Yunnan University of \\ Finance and Economics \\ Kunming, China \\ 123278697@qq.com
}

Wenjing Zhao*

\author{
Statistics and Mathematics School, Yunnan University of \\ Finance and Economics \\ Kunming, China \\ Dan Wu \\ International Business School, Yunnan University of \\ Finance and Economic \\ Kunming, China
}

\begin{abstract}
In recent years, the living standards of people continue to improve with the rapid development and rise of China. The Chinese tourism and real estate industry have become an vital strength of economic contribution in China. The coordinated development and relationship between the industries have attracted more and more attention of a lot academic researchers in China. For instance, Zhang (2012), a Chinese scholar, discovered that the development of tourism in Hainan, a Chinese tourist city, promoted the rising of real estate prices, with the overheated phenomenon of real estate speculation. Moreover, Yunnan province as the well-known tourism province in China, its real estate speculation seems to is unconscious than Hainan. Whether or not the influence of tourism industry on regional real estate prices really exists, this has no relevant research conclusion.
\end{abstract}

The aim of this study is that research the influence of tourism development on local real estate prices and takes several representative tourist cities as cases in Yunnan Province by descriptive statistics and graphic summaries in case study analysis.

The author through analysis reached that In the first place, Tourism income has the greatest impact on local real estate prices. In the second place, tourism income has a greater impact on local real estate prices. In the third place, the economic development of the region has a general impact on local housing prices. All above, the development of tourism has a greater impact on local housing prices.

Keywords—real estate industry; tourism

\section{INTRODUCTION}

Tourism has become the one of the largest and most significant industries with the development on global economy. Shao deemed that the economic growth of Global tourism has been generally higher than the global economic growth. What's more, tourism has gradually become the largest emerging industry in the world, which has surpassed the oil industry since 1960s. Meanwhile, the WTCF forecasted that the global tourism revenues will climb to the 16 trillion dollars in 2020, which nearly occupied $10 \%$ of the global GDP. China owns abundant resources of cultural tourism and natural tourism. China has transferred to an advanced tourism country, which has achieved outstanding results on tourism industry development since 1970s. In addition, China has become the largest domestic tourism market and the fourth largest tourist destination country in the world. China is in the golden period of tourism development, not only because the great space of tourism development in China, but the influence with tourism growth as well. Therefore, the development of the tourism industry owned a significant research value in China.

Statistics from the CNBS showed that the average selling price of commercial housing from 3366.79 yuan $/ \mathrm{m}^{3}$ rised to 6793 yuan $/ \mathrm{m}^{3}$ from 2006 by 2015 on the average increasing of 7.95\%. Some people have a negative attitude about the development of Chinese real estate industry, but some people are optimistic. Wang who is chairman of Wanda Group that is one of the largest Chinese commercial real estate Group, announced completely withdraw from the real estate to light assets in china, he thought that China industry cycle is too strong, resulting in cash flow instability and investment expectation is easy to change frequently.

The development of real estate industry and tourism industry, as an important indicator of China's regional economy, affects the trend of the economy. The development of tourism has a more or less influence on regional economy in China. Tourism how to affect the real estate prices in the region, which worth discussing.

\section{LITERATURE REVIEW}

The classical agricultural location theory and industrial location theory are static analysis based on a certain industry or general equilibrium at a micro level, emphasizing the decisive role of transportation and labor costs.

German economist Thunen, the founder of classical regional economic theory, put forward that the agricultural location choices not only relate to the land natural attributes, but also relate to local economic conditions. Besides, land and agricultural products sales distance play the critical role. The

*Corresponding author 
location issues of the iron and steel industry emerged with the development of industrialization in western Europe, and thus a large number of scholars studied the problem actively. The German economist Launhaldt as representatives, who applied the concept of regional triangle which was made of the sales market, fuel production and raw materials as basis, suggested that the best location of the plant should be selected according to the principle of lowest production cost. In the early twentieth Century, the German economist Webb argued that the selection of industrial location should not only consider the transportation cost, but also consider the agglomeration factors and costs of production, and systematize the industrial regional theory.

On behalf of the regional balanced development theory of new classic, swan and Ross model proposed that regional differences narrow with regional economic growth. At the same time, balanced growth is a long-term with nonbalanced growth is short $(\mathrm{Xu})$. Rodan put forward big-push theory, thought to invest the related industries, which can reduce the industry cost, improve the profit rate and create mutual demand market, in order to expand the market and eliminate the bottleneck caused by insufficient supply. some backward areas possess, nevertheless, the limited amount of investment that put into mutual multiple industries, which is hard to achieve balanced regional development.

As a result, Myrdal, as a representative of the unbalanced development theory, argued that economic development is unbalanced, and the economic industry or department should focus on the development of the industry with the greatest relevance effect to promote the development of related industries. Scholars disputed about the location is based on balanced development or nonbalanced development model to promote economic development. Williamson provided empirical research based on the inverted $U$ hypothesis, which showed that the disparity of regional development will tend to unbalanced development in initial stage of regional development, and regional development will tend to balance with the economic development.

Chinese scholars such as Yu and Wang applied statistics analysis to research the relationship between per capita income and real estate price index from 2001 to 2006 in the Chinese Tianjin, which discovered that the tourism development push commodity prices and housing prices to rise, resulting in local residents purchase house difficultly and cause tourism revenue loss.

Liu elaborated that real estate prices of Chinese Hainan lose balance in most of the time by using Grainger causality experiment and case study, which easily comes into being overheating or depression of the real estate. The main reason is that the tourism development attracts a large amount of investment and demand increasing for tourism property sharply, which leads to the imbalance of real estate prices. Liu found a sharp rise in real estate prices is not obvious on the domestic tourism population, or even inhibit. The relationship between the rising of real estate prices and the tourism growth is inconspicuous.

Through literature collection, most scholars hold that the tourism development is positively correlated with the real estate prices, however the effect of interaction is both advantages and disadvantages. The negative impact is the value of real estate is overestimated in tourism areas, resulting in the phenomenon that the local residents cannot bear the high housing prices and curb consumption. Moreover, Tenxun Real Estate supported that there are a positive impact. Raising of real estate prices can promote the development of a lot building materials industry, so as to provide more employment opportunities. All in all, Scholars study the impact of tourism development on housing prices, using statistical analysis and case analysis methods are in the majority.

\section{DATA DESCRIPTION}

The first place, the four cities of data collection is Kunming, Lijiang, Dali, Jinghong in Yunnan province. Data collection includes the regional real estate prices are represented by commercial housing sales divided by the commercial housing sales area, the regional tourism income, tourism population, per capita GDP on behalf of the regional economic development. At the same time, data collected from 2007 to 2016 years in four cities. The specific data are in Appendix. It is noteworthy that the commodity house is Buying and selling houses on the market, including commercial residential building, commercial house and other buildings in trade.

The second place, the data resources come from the relevant literature and periodicals are consulted in the library and the authoritative academic website. Such as the 'Chinese tourism Yearbook', 'Yunnan Statistical Yearbook', 'the national economic and social development statistics in Yunnan', National, provincial and Municipal Statistics bureaus, Tai'an database to collect data.

Data resources come from second resources and belong to public data according to the data characteristic of this dissertation. Data obtained from official and authoritative websites or libraries can save time and cost to improve the validity of data as a result of the economic data such as tourist population and tourism income are large and complicated.

In 2016, there were seventy-six scenic spot in Yunnan above 4A class, and the number of scenic spot in the four cities ranked in top four with accounting for $48.68 \%$. Kunming had the most scenic spots above 4A level, reaching 11 scenic spots (MCTPRC). Meanwhile, Kunming, the capital of Yunnan province. Possess special geographical and economic advantages, so has the largest scale of traffic and reception in tourism. The humanities and natural scenic spots in Lijiang and Dali, the most representative cities of Yunnan tourism, are plentiful and diverse, and have been appraised as excellent tourism cities by many times in china. Jinghong, Xishuangbanna, has a distinctive culture due to its border with Burma and abundant flora and fauna, which has been nominated as an excellent national tourist city many times.

A brief introduction to the tourism situation of four cities is made from above, which can be known that the four cities are typical tourist cities and the degree of tourism development is relatively developed and perfected compared with other cities in Yunnan province, although the four cities are distinct in administrative level, location and scale. 


\section{DATA ANALYSIS}

From table I can obviously see the growth degree of tourism income since the 2007 to 2016 in the four tourist cities. the tourism income of the four cities are growing persistently, and Kunming tourism income has remained highest. because urban size of the four cities is different, so the author focus on the degree of spread and average of the tourism income growth to represent the development of the tourism income.

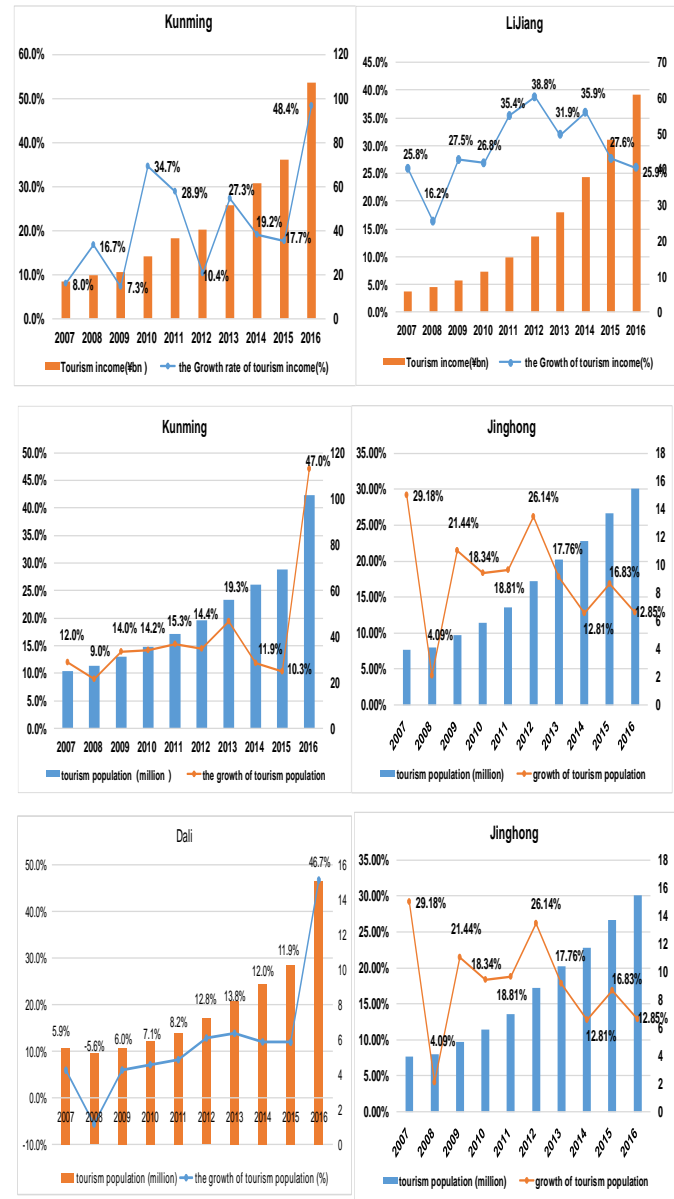

Fig. 1. The growth of tourism income in four cities

First of all, the tourism population from chart 2 shows that the tourism population of Kunming was still the largest and the average tourist population was 49.65 million, followed by Lijiang, jinghong and Dali. Then, from the perspective of the growth of tourist population, tourism population growth of Lijiang is no less than $14.72 \%$ in the ten years, followed by tourist population growth of Kunming and jinghong were not lower than $10 \%$ in the other years except 2008, and the Dali appeared a negative growth in 2008 and the first five years growth is lower than 10\%. From 2013 to 2016, the growth tendency of tourism population ,in the Kunming and Dali, slowly reduce in last two years, but the growth has a breakthrough to $40 \%$ in 2016 . However, the growth rate of jinghong and Lijiang has been decreasing gradually from 2013 to 2016.

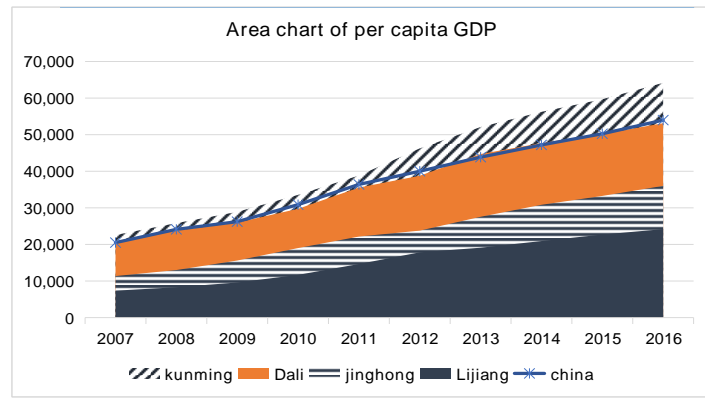

Fig. 2. The area chart of per capita GDP in four cities

As can be noticed from chart 3, Kunming has the largest per capita GDP and followed by Dali, jinghong and Lijiang. The average per capita GDP in Kunming is small gap with Dali from 2007 to 2011, but since 2011, the gap between GDP per capita with Dali had gradually widened and the GDP per capita had been the highest in four cities. The per capita GDP of jinghong and Lijiang is relatively small in the ten years.

In 2016, the per capita GDP of China is 53,980 yuan. In four cities, Kunming has always been higher than per capita GDP of China, while Dali is basically the same as the average level of China.per capita GDP of Lijiang and Dali are very lower than China. As can be seen from table 5, the growth rate of pen is slightly higher than others and yet the standard deviation of the growth is largest with $6.98 \%$ in Lijiang. At the same time, Lijiang as a prefecture-level city that per capita GDP is far below Dali, jinghong these county-level cities. In contrast, average GDP per capita of Dali in the county-level cities is only 5369 yuan from Kunming, the most developed city in Yunnan province, and it is not volatile.

From the concentration and dispersion degree of tourism income growth, know that the growth of tourism income and population in Lijiang is the best, followed by Jinghong, Dali and Kunming. meanwhile the development level of tourism income has continuous improvement in the four cities, which showed that the development of tourism income and population had entered a mature stage in Lijiang and Jinghong. On the other hand, the fluctuation of Dali and Kunming is large and the average growth is slow, which showed that the development of tourism income and population in Dali and Kunming was not mature than Lijiang and Jinghong. Nevertheless, Dali and Kunming, in recent years, had been developing rapid and has great potential for tourism.

In general, the per capita GDP in Kunming is the highest and the growth fluctuation is least in the four cities. The second is that Dali and Jinghong have shown better performance as county-level cities, while the per capita GDP of Lijiang is not high, but it is growing fast. Therefore, economic development level of Kunming is higher than the other three cities, followed by the level of economic development in Dali is same with China basically. the economic development level of Jinghong and Lijiang is relatively poor in these ten years, but the speed of development is becoming faster and faster.

The real estate prices in Kunming and Dali were higher and the average growth rate was the slower than the other two cities. However, the volatility of real estate price in Kunming fluctuates was smallest while the volatility in Dali was higher. 
Secondly, although the real estate prices in Jinghong had fluctuated around 5000 yuan in recent years, it was lower than the other three cities, but the performance of growth and volatility of real estate prices was better in four cities. Real estate prices in Lijiang is growing faster, especially in recent years, even in 2016 over Kunming to be the first in the four cities, but the volatility of real estate prices is largest, which showed that the real estate price situation in recent years was great when the volatility risk is also large.

\section{CONCLUSION}

It is very necessary to carry out this research, because the author discovered that there are few literature about the impact of regional tourism development on real estate prices by reviewing a great deal of literature. At the same time, tourism development of Hainan and Sanya has promoted the rising of local real estate prices in China, which have the opposite effect to the development of local tourism and increasing the living cost of local residents.

The economic level of Yunnan province is underdeveloped. The author find out the tourism development how to impact the local real estate prices through related research in Yunnan Province, which is benificial to analyse the healthy development of tourism and real estate and put forward effective recommendation in Yunnan.

The implications of results will be further discussed to the healthy development of tourism and real estate price. the first implication, a regional economy is undeveloped and the tourism industry developed in the long term, the development of the tourism industry will promote local real estate prices, especially, when the tourism income and tourist population growth faster, but the fluctuations of real estate price also will become large. While the economic development level of the region is steadily increasing, which has a medium impact on the price of real estate. In other words, when the real estate price in a region is rising for a long time, the development of tourism in this region may be in a period of prosperity.

\section{ACKNOWLEDGMENT}

Thanks the supporting of Yunnan Province Applied basic research project 2016FD062.

\section{REFERENCES}

[1] W. Launhaldt, Mathematical Proof of Allergy Economic Theory. Rostock:Chemical Press.

[2] R.W. Liu. A study on the rationality of real estate price: taking Hainan as an example--on the application of co integration relationship in monitoring real estate prices. Hainan Finance, 2008, 241 (12), pp. 36-41.

[3] J.Y. Liu. Will Tourism Promote Housing Prices? -- Empirical Research Based on China's Provincial Data, Tourism Science, 2013, 27 (2), pp.2529.

[4] K.G. Myrdal. Economic theory and undeveloped regions, London : Duckworth.1957.

[5] Q.H. Shao, The Goal of Tourism is a Strategic Pillar Industry, Travel Daily, 31st August 2012. [Online]. Available at: http://www.traveldaily.cn/article/64141 [accessed: 1st November 2017]

[6] V. Thunen. The Relationship Agriculture and National Economy with Isolated Country. Rostock: Germany Economy Publishing.1825.

[7] A. Weber. Industrial Location Theory: the pure theory of location. Chicago: Chicago University Press.1909.

[8] J.G. Williamson. regional inequality and the process of national development: A description of the patterns, economic development and cultural change, 1965, 13(2), pp.560-570.

[9] P.R. Rodan. Problems of Industrialization of Eastern and South- Eastern Europe. London : La Riforma Social.1943.

[10] Xu, Y.S. Regional economic theory: Historical review and Research Summary. Journal of Shijiazhuang Tiedao University (Social Science Edition), 2004, 8 (3), pp.8-14. 